\section{The Edinburgh Dental Dispensary 1860 to 1879}

\author{
P. Sutcliffe ${ }^{1}$
}

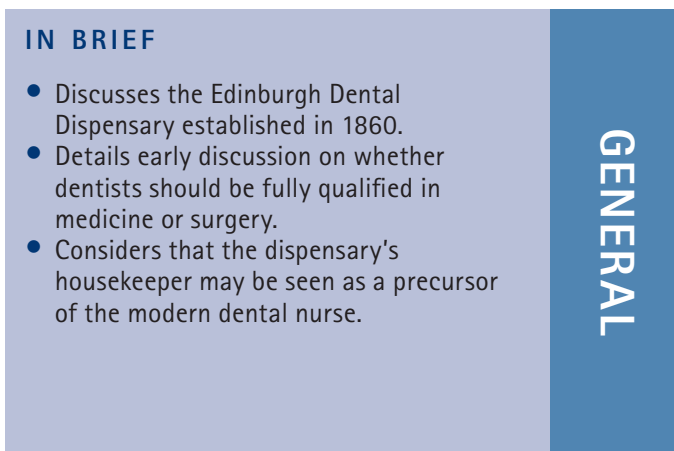

The Edinburgh Dental Dispensary began in 1860 as a private charity to provide free treatment for the poor and to teach
students. In 1862 the dispensary became a public charity in new premises with a committee of managers. Dental students
were admitted in 1864. By 1867 the annual number of patient attendances was about 4,000 and the mainstay of treat-
ment was extraction. Housekeepers were the only support staff. The dispensary was constantly impecunious; in 1869 the
managers considered discontinuing the service. In February 1879, following the 1878 Dentists Act, the dispensary was
merged into the new Edinburgh Dental Hospital and School.

\section{INTRODUCTION}

In the middle of the nineteenth century quacks were common. The best available forms of training in dentistry were apprenticeships but these were mainly directed towards mechanical dentistry and provided no understanding of physiology, pathology or the principles of treating dental diseases. ${ }^{1,2}$ In 1856 John Smith instituted a course of lectures in dentistry at the Medical School in Edinburgh Surgeons' Hall, which was open to dental as well as medical students. ${ }^{3,4}$ Two years later an amending clause to the Medical Act of 1858 enabled the Royal College of Surgeons of England to award the LDS diploma. ${ }^{1}$ In the same year Smith wrote to Dr Robert Omond, President of the Royal College of Surgeons of Edinburgh, urging the college to establish a qualification in dentistry. ${ }^{2}$ However the college's position remained unchanged that dental practitioners should be fully qualified in surgery. ${ }^{5}$ In 1860 Smith persuaded three colleagues to join him and open a dental dispensary in Edinburgh, which would augment his course of lectures with

'Emeritus Professor, University of Edinburgh,

5 Tantallon Place, Edinburgh, EH9 1NY

Correspondence to: Dr Philip Sutcliffe

Email:w_psutcliffe@yahoo.co.uk

\section{Refereed Paper}

Accepted 5 Januray 2012

DOI: 10.1038/sj.bdj.2012.312

${ }^{\circledR}$ British Dental Journal 2012; 212: 387-389 practical instruction. ${ }^{4}$ His collaborators were Robert Nasmyth, ${ }^{3,6}$ Francis Brodie Imlach $^{7,8}$ and Peter Orphoot. ${ }^{9}$

In 1858 Smith had begun to demonstrate his charitable skills by joining forces with an Edinburgh physician, Charles Wilson and The Scotsman newspaper to launch a very successful appeal for funds to establish a children's hospital in Edinburgh. In May 1863 Meadowside House was opened as a 44 bed hospital for children under the patronage of Queen Victoria. ${ }^{10}$

\section{THE BEGINNING OF AN EXPERIMENT}

The Edinburgh Dental Dispensary was first opened at 1 Drummond Street. Patient attendances during 1860 and 1861 were 250 and 270 respectively; sufficient to encourage the dispensary's founders to develop a public charity staffed by medical officers and two consulting surgeons, Professor Goodsir and Mr Spence. ${ }^{8}$

The founders then approached a group of 'medical men' to frame a constitution and become the dispensary's managers. All who were approached agreed to take part. They were: Dr Craigie, President of the Royal College of Physicians; Dr Newbigging, President of the Royal College of Surgeons (both ex officiis); Professors Goodsir, Christison and Simpson; Doctors Begbie, Burt, Spence, Duncan and Omond. A minute book was opened to record their first meeting on 14 January 1862 . This is now held in the Lothian Health Services Archive at the University of Edinburgh Centre for Research and is the source of much of the following narrative. ${ }^{11}$

The managers began by establishing the qualifications to be required of the dispensary's clinicians. Surgeon-dentists, qualified in medicine or surgery were clearly acceptable. Dentists with the LDS of the Royal College of Surgeons of England presented a problem as Professor Christison saw the diploma as a partial qualification in surgery, which was insufficient for a teacher. ${ }^{12,13}$ With some misgivings it was decided not to approve the LDS qualification. Notwithstanding this decision, the managers recognised that experienced practitioners with no formal qualifications could be capable of performing satisfactorily as medical officers, provided that by 26 May 1862 they had 20 years experience of the practise of dentistry in Edinburgh.

In June 1862, after a long search for better premises, the dispensary moved in with the Eye Dispensary at 54 Cockburn Street for an annual rent of $£ 15$ 'inclusive of coal, gas and attendance. ${ }^{11}$ The following November, William Kelso Thwaites, solicitor before the Supreme Courts of Scotland, was appointed honorary secretary and treasurer to the dispensary.

\section{THE NUMBERS OF PATIENTS}

In those days it was not unusual for dentists to offer free treatment to the deserving 
poor and to allow apprentices to treat the 'gratis patients. ${ }^{14}$ Similarly, one of the dispensary's officers was in attendance every morning between nine and ten o'clock except for Sundays and holidays.

The move to 54 Cockburn Street was associated with a dramatic increase in patient attendances to 1,404 during the 11 months from June 1862. This increase strained the facilities of the Eye Dispensary, prompting a request to increase the rent by $£ 5$. This was rejected by the Dental Dispensary's managers who chose to move to 38 Cockburn Street as the sole tenants for a rent of $£ 21$ for the first three years increasing to £25 for the next two years. Attendances increased steadily to more than 3,600 for the year ending April 1867. Afterwards the reports were less precise referring to "considerably upwards of 4,000' and 'thousands of patients annually: ${ }^{11}$

As time progressed the Dental Dispensary's managers became increasingly aware that the well-to-do were sending their families to the dispensary while omitting to offer payment. It was resolved to exclude these patients, but it was not until January 1877 that the chairman reported the abuse had been successfully stopped.

\section{A MEAGRE EXCHEQUER}

Initially, the dispensary's founders had paid all the bills and had not charged for their services. As a public charity the medical officers continued to work without payment but 'invariably with a meagre exchequer. ${ }^{15}$

Money was raised by advertising and by circulating printed leaflets followed by an agent who made door to door collections. Charitable organisations were approached for support and a box was placed in the dispensary for patients' contributions. After coping with an increasing number of patients and a decreasing income, it was found by exercising very strict economies some £58 was needed annually to keep the dispensary going; a sum which is broadly equivalent to today's buying power of $£ 4,800 .{ }^{16}$ From the outset income from donations and subscriptions failed to meet costs. Patients' contributions provided only £3-4 annually.

By March 1869 income for the year was so poor it was resolved to avoid 'suspending' the dispensary by publishing a strongly worded report in a final attempt to increase subscriptions. This yielded an additional $£ 100$, which enabled the dispensary to continue.

Luckily the spring of 1871 brought an unexpected grant from a trust set up by the Messrs Laurie, Merchants of New York and natives of Scotland, for distribution among the charitable institutions of Edinburgh. With this and earlier grants from a trust in the name of John Mackenzie of Manor Place Edinburgh, the dispensary was able to recover from its earlier 'very depressed condition of several years standing' by 1872. ${ }^{11}$ Sadly by December 1874 the collections for the year had fallen well below those of the previous year. As a result the dispensary moved for the third time to 46 Cockburn Street, where the rent was lower. In February 1878, the year preceding the incorporation of the dispensary with the new Dental School and Hospital, the secretary was once again forced to declare that contributions and subscriptions had not improved, with the great depression in trade, the high price of provisions and the demands of the Blantyre Fund following Scotland's worst mining disaster ${ }^{17}$ given as reasons.

\section{DENTAL TREATMENT}

Initially, and probably throughout the entire existence of the dispensary, the mainstay of treatment was tooth extraction as lack of money restricted the development of restorative care. In 1876 the supervising dentists complained to the managers: 'your Committee (of Medical Officers) would therefore recommend a small supply of stopping to be maintained, much of the supply lately coming out of the pockets of the medical officers.' ${ }^{11}$

General anaesthetics could not be afforded. Following a lively discussion at the annual general meeting in January 1876, it was concluded it was impossible to meet the cost of anaesthetic agents and apparatus without raising a special subscription of $£ 15-20$. A year later it was announced there had been no response to the appeal.

In 1877 the contemporary historian Alfred Hill shared the bewilderment of the dispensary's managers and medical officers at the lack of public support for a charity which had proved to be a distinct necessity in benefiting the suffering poor. In his view the insufficient supply of funds had crippled the development of the dispensary, particularly with regard to the lack of nitrous oxide anaesthesia and also the limit on tooth restoration. He pointed out that patients were not the sole beneficiaries of improvements in treatment but students also gained from the experience. ${ }^{15}$

\section{HOUSEKEEPERS}

A Mr Gough was appointed housekeeper when the dispensary was moved to 38 Cockburn Street. He was granted three tons of coal per year for his own use provided that a fire was kept in the operating room during the winter from nine to ten o'clock every weekday morning. Six months later Mr Gough was in prison for an unspecified crime. A new housekeeper, Mrs Hill, was appointed under conditions which essentially were those of a domestic servant: 'that the premises be kept clean and in such order as the committee shall require; that the operating room shall be always ready and in order at the visit hour and that the housekeeper be in attendance at the time of the visit; that patients waiting on the medical officers of the day shall have an opportunity of accommodation in the housekeeper's room as the committee may arrange; that she should make herself generally useful as occasion may require..'1 No salary was attached to these duties but the accommodation was rent free with an allowance of coal and gas. By May 1865 Mrs Hill had exclusive use of her room and the operating room also served as the waiting room. Eventually, Mrs Hill was reengaged as a non-resident attendant for an annual salary of $£ 10$ and her room was converted into a waiting room.

\section{THE LICENCE IN DENTAL SURGERY}

The Medical Act of 1858 enabled the Royal College of Surgeons of England to award the LDS diploma. Candidates were required to have successfully completed four years of study, which included teaching in basic and clinical sciences at a recognised medical school, practical experience of mechanical dentistry, attendance at a recognised dental hospital or dental department and teaching in the basic and clinical sciences relevant to dentistry at a recognised school. In May 1865 an approach was made to the Royal 
College of Surgeons of England seeking recognition of attendance at the Edinburgh Dental Dispensary for candidates who were preparing for the LDS examination. The board of examiners at the Royal College of Surgeons readily agreed, providing the Edinburgh candidates attended one of the London schools for six months since there was no recognised dental school in Edinburgh. The effect of this condition was to reduce necessary attendance in London from 30 months to 6 . It was estimated that the reduction by two years would result in a saving of about $£ 100$ for each student. An equivalent sum today would be about $£ 9,400$ per student. ${ }^{16}$

\section{DENTAL STUDENTS}

In May 1864 the dispensary's student fees were three guineas for six months of instruction, two guineas for three months and one guinea for one month. The fee for registered medical students was one guinea for one month. In those days candidates for admission to the Army Medical Service were encouraged to have attended a course in dentistry. ${ }^{3}$

The first students recorded in the accounts are Alfred Wright and John Crichton who paid two guineas and one guinea respectively on 10 December 1864 . The accounts, which do not appear in the minute book after 1867, yield the names of only five more students. Most of them were qualified or qualifying in medicine but there is a reference to an un-named student studying for the LDS examination. Such low numbers of students may have been typical for the time. ${ }^{18}$

\section{THE DENTISTS ACT 1878}

Disappointment over the slow growth of interest in the LDS examination gave way to a recognition of the effectiveness of the medical register 'as a means of allowing the public to distinguish between the qualified and the quack. ${ }^{19}$ In London in
1876, Charles James Fox established the Dental Reform Committee to bring about a register of qualified dentists by means of an Act of Parliament. ${ }^{19}$

With this in mind, in 1877 John Smith, as a member of the Dental Reform Committee, convened a meeting attended by two thirds of Scotland's practising dentists to explore the means of regulating dental practice and registering qualified practitioners. ${ }^{3}$ The meeting appointed a Scottish Dental Education Committee with John Smith as its chairman and William Bowman MacLeod the secretary. MacLeod wrote to the trustees and managers of the Edinburgh Dental Dispensary requesting a meeting where it was agreed, pending the successful passage of the Dentists Bill and the requirement to form a dental school, the dispensary could become its nucleus in combination with the museum of the Odonto-Chirurgical Society.

Successful passage of the Dentists Bill in July 1878 enabled the Royal College of Surgeons of Edinburgh to establish a Dental Examining Board and a Licence in Dental Surgery; although, as John Smith was to observe "not without some dissentients'.

In September 1878 the premises at 18 Brown Square (to be renumbered 30 Chambers Street) were secured for the Dental School and Hospital at an annual rent of $€ 100$.

On 1 February 1879 the Edinburgh Dental Hospital and School became formally incorporated with the Edinburgh Dental Dispensary. In the proud words of the account of the merger, the dispensary had been 'for nearly twenty years previously the only institution of a dental educational character in Scotland'. ${ }^{20}$ On 30 October 1879 at a meeting held in the medical school three of the four founders of the 1860 Dental Dispensary had the satisfaction of attending the inauguration of the Edinburgh Dental Hospital and School. ${ }^{20,21}$
Sadly, Robert Nasmyth had died on 12 May 1870 at the age of 78, only two months after he had ceased from practising.

The author gratefully acknowledges the help received from the staff at the Centre for Research Collections at the University of Edinburgh; Ms Marianne Smith, College Librarian and Mr Steven Kerr at the Royal College of Surgeons of Edinburgh.

1. Hillam C. The providers of dental treatment. In Hillam C (ed) The roots of dentistry. pp 40-42. London: British Dental Association, 1990.

2. Smith J. On the present position of dental surgery and its advancement as a branch of medical education. Edinburgh: Sutherland and Knox, 1858.

3. Campbell J M. Dentistry then and now. 3rd ed. Glasgow: printed privately by Bell and Bain Ltd, 1981.

4. Smith J. The origin, progress and present position of the Royal College of Surgeons of Edinburgh 1505-1905: fourth centenary of the college July 1st, 1905. Edinburgh: Royal College of Surgeons Edinburgh, 1905.

5. Smith J. Draft suggestions submitted to the meeting of dentists at Edinburgh for the regulation of the practice of dentistry and the registration of dental practitioners in Scotland. Royal College of Surgeons of Edinburgh Archive 1877; GD2/15.

6. Anon. Robert Nasmyth, Esq., FRCSE. Edinburgh Med J 1870; 15: 1149-1150.

7. Obituary: Francis Brodie Imlach FRCS. Edinburgh Med J 1892; 37: 773-775.

8. Masson A H B. Portraits, paintings and busts in the Royal College of Surgeons of Edinburgh. Edinburgh: Royal College of Surgeons of Edinburgh, 1995.

9. Peter Orphoot, MD Edin. Br Dent J 1914; 35: 45-46. 10. Guthrie D. The Royal Edinburgh Hospital for Sick Children, 1860-1960. Edinburgh and London: Livingston Ltd, 1960.

11. Minute book: Edinburgh Dental Dispensary, Jan 1862-Dec 1878. Lothian Health Services Archive; LHB25/1/1/1.

12. Horn D B. A short history of the University of Edinburgh: 1556-1889. Edinburgh: Edinburgh University Press, 1967.

13. Comrie J D. History of Scottish medicine. 2 nd ed. London: Baillière, Tindall and Cox, 1932.

14. Woodhouse AJ. Reminiscences of fifty-four years in the dental profession. J Br Dent Assoc 1897; 18: 22-23.

15. Hill A. The history of the reform movement in the dental profession in Great Britain during the last twenty years. London: Trübner and Co, 1877.

16. Bank of England. Inflation Calculator. Threadneedle Street, London, EC2R 8AH.

17. Blantyre pit explosion (1877). In Keay J, Keay J (eds) Encyclopaedia of Scotland. pp 86. London: Harper Collins, 1994.

18. Smith E, Cottell B. A history of the Royal Dental Hospital of London and School of Dental Surgery 1858-1985. London: Athlone Press, 1997.

19. Donaldson J A. The National Dental Hospital 1859-1914. London: British Dental Association, 1992.

20. Report of the Edinburgh Dental Hospital and School for 1879-1880. Edinburgh: Edinburgh Dental Hospital and School, 1880.

21. The Edinburgh Dental Hospital and School. Br J Dent Sci 1879; 22: 102-103. 